\title{
The role of contraception in preventing HIV-positive births: global estimates and projections
}

\author{
Jennifer Sherwood ${ }^{1,2^{*}} \mathbb{D}$, Elise Lankiewicz ${ }^{1}$, Beirne Roose-Snyder ${ }^{3}$, Bergen Cooper $^{3}$, Austin Jones ${ }^{1}$ and \\ Brian Honermann ${ }^{1}$
}

\begin{abstract}
Background: Meeting the contraceptive needs of women living with HIV (WLHIV) has primary health benefits for women, in addition to being a key element to prevent mother-to-child HIV transmission. This analysis will estimate the current number of infant HIV infections prevented by contraception in the era of increased HIV treatment coverage and; 2) model the additional HIV benefits of preventing unintended births to WLHIV.

Methods: Secondary data analysis was conducted using publicly available data from the United Nations Programme on HIV/AIDS (UNAIDS) and Population Division, Demographic Health Surveys, and peer-review literature. National data from 70 countries, that had a UNAIDS estimate for the number of WLHIV nationally, were combined into country-level models. Models estimated the current number of infant HIV infections averted by contraception annually and potentially averted if unintended births to WLHIV were prevented. Estimates take into account pregnancy and live birth rates, contraceptive coverage, contraceptive method mix and failure rates, and HIV treatment coverage during pregnancy to prevent mother to child transmission.

Results: Contraception use among WLHIV prevents an estimated 43,559 new infant HIV infections annually across 70 countries. Countries with the largest number of infant infections averted by contraception included South Africa (9441), Nigeria (4195), Kenya (3508), Zimbabwe (2586), and India (2145). Preventing unintended births to WLHIV could avert an additional 43,768 new infant infections per year, with the greatest potential gains to be made in South Africa (12,036), Nigeria (2770), Uganda (2552), and the Democratic Republic of the Congo (2324).

Conclusions: Contraception continues to play an integral role in global HIV prevention efforts in the era of increasing HIV treatment coverage, especially in sub-Saharan Africa. Broad contraceptive availability, increased contraceptive voluntarism and method mix are key components to preventing unintended births and ending new infant HIV infections worldwide.
\end{abstract}

Keywords: Contraception, HIV, Women, Antenatal HIV, Prevention, Family planning

\footnotetext{
* Correspondence: Jennifer.sherwood@amfar.org

'Public Policy Office, amfAR, Foundation for AIDS Research, 1100 Vermont Avenue NW, Suite 600, District of Columbia, Washington, DC 20005, USA

${ }^{2}$ Department of Population, Family, and Reproductive Health, Johns Hopkins Bloomberg School of Public Health, Baltimore, MD, USA

Full list of author information is available at the end of the article
}

(c) The Author(s). 2021 Open Access This article is licensed under a Creative Commons Attribution 4.0 International License, which permits use, sharing, adaptation, distribution and reproduction in any medium or format, as long as you give appropriate credit to the original author(s) and the source, provide a link to the Creative Commons licence, and indicate if changes were made. The images or other third party material in this article are included in the article's Creative Commons licence, unless indicated otherwise in a credit line to the material. If material is not included in the article's Creative Commons licence and your intended use is not permitted by statutory regulation or exceeds the permitted use, you will need to obtain permission directly from the copyright holder. To view a copy of this licence, visit http://creativecommons.org/licenses/by/4.0/. The Creative Commons Public Domain Dedication waiver (http://creativecommons.org/publicdomain/zero/1.0/) applies to the data made available in this article, unless otherwise stated in a credit line to the data. 


\section{Background}

There are an estimated 14.7 million women of reproductive age (15-49) living with HIV, accounting for nearly $40 \%$ of the global HIV burden. In East and Southern Africa, the regions most impacted by HIV, adult females $(15+)$ make up the majority (58\%) of people living with HIV [1]. Accordingly, addressing the impact of HIV on this population is central to efforts to end the HIV pandemic and improve the wellbeing of millions of women across the globe; moreover, better serving this population may further HIV prevention efforts given the potential of mother-to-child transmission of the virus during pregnancy, labor or breastfeeding. In 2018, there were an estimated 160,000 new HIV cases among children aged $0-9$, the overwhelming majority of which are attributable to MTCT [2].

Efforts to prevent mother-to-child transmission (PMTCT) have been focused in four areas: primary prevention of HIV among women of childbearing age, preventing unintended pregnancies among women living with HIV (WLHIV), preventing transmission between WLHIV and their infants, and providing treatment care and support to mothers living with HIV, their children, and families [3]. Accordingly, two key components of these efforts have been ensuring pregnant women are on effective antiretroviral therapy (ART) and providing accessible voluntary contraceptive resources to prevent unintended pregnancies. Continual ART for mothers and short-term regimens for newborns can reduce the likelihood of HIV transmission from 15 to $45 \%$ to less than 5\% [4]. Globally, ART coverage of women during pregnancy has nearly doubled since 2010, from 44 to $82 \%$; however, wide country and regional disparities remain [1].

In contrast to the recent progress made in ART coverage for pregnant women, growth in contraceptive prevalence has followed a slower trajectory, with persistent demonstration of unmet need globally [5]. In 2017, an estimated 214 million women in low and middle income countries wished to avoid pregnancy but were not using a modern contraceptive method [6]. The highest proportion of these women were in Sub-Saharan Africa, the region which also bears the highest burden of HIV [1]. Even where modern contraception is available, women and girls may face limited options in method mix. Limited contraceptive options represents an additional barrier in addressing unintended pregnancies, given that expanded options are associated with increased contraceptive prevalence [7].

Globally, the proportion of births that are unintended is also substantial. From the period of 2010-2014, nearly a quarter of births globally were unintended, and in Southern Africa, the Caribbean, and South America, more than half of births were unintended [8]. Unintended births are commonly defined as births that occurred sooner in one's life than desired or were not wanted at all [9]. Given that the primary contributors to unintended births include non-use or unmet need for family planning services and contraceptive failure [10], it follows that a critical avenue to ensuring women's full reproductive control includes increasing access to voluntary family planning services.

Voluntarism in family planning services refers to the ability of patients to make a full, free and informed choice about their reproduction and reproductive health services, without any force, coercion or undue incentivization [11]. Voluntarism is vital in all health services, but the need to safeguard voluntarism and contraceptive choice for WLHIV is particularly acute given persistent reports of forced or coercive experiences with family planning programs $[12,13]$. Throughout this paper, any reference or recommendations related to family planning programs or expansion of contraceptive access are referring to services implemented with full informed choice and rigorous human rights safeguards in line with World Health Organizations guidelines [14].

Meeting women's contraceptive needs has numerous health benefits for the individual, which deserve discussion, including reducing maternal mortality and morbidity $[15,16]$. However, the primary focus of this paper is on the additional HIV benefits of meeting the contraceptive needs of WLHIV - a key element of PMTCT efforts, which has yet to be fully realized [17]. Previous estimates (2008) have calculated that contraception prevented over 200,000 new HIV positive births annually in President's Emergency Plan for AIDS Relief (PEPFAR) countries $(n=15)$ [18]. This previous estimate, however, assumed the absence of ART coverage for PMTCT. Accounting for recent positive changes in ART coverage for PMTCT and contraceptive method mix (CMM), the current analysis builds on previous work to examine 1) The number of new HIV cases averted annually due to contraceptive usage, and 2) the number of additional HIV cases that may be averted if unintended births to WLHIV were prevented.

\section{Methods}

\section{Data sources}

All data are sourced from publicly available datasets from the Joint United Nations Programme on HIV and AIDS (UNAIDS) [19], the United Nations Population Division, Department of Economic and Social Affairs (UN DESA) [20], country Demographic Health Surveys [21], Family Planning 2020 [22], Guttmacher [23], and other peer-reviewed literature. The full set of data sources is available in Table 1. All countries with an UNAIDS estimate for the national number of WLHIV were included, except countries for which the total 
Table 1 Data sources

\begin{tabular}{|c|c|c|c|}
\hline Indicator & Description & Main Source(s) & Notes \\
\hline WLHIV of reproductive age & $\begin{array}{l}\text { Number of WLHIV aged } 15 \text { to } 49 \text { years } \\
\text { old, country specific data }\end{array}$ & $\begin{array}{l}\text { Joint United Nations Programme on } \\
\text { HIV and AIDS (UNAIDS), } 2018 \text { [1] }\end{array}$ & $\begin{array}{l}\text { Global Health Data Exchange (GHDx) } \\
2018 \text { data were used where UNAIDS } \\
\text { data were not available for } 2018 \text { [24] }\end{array}$ \\
\hline $\begin{array}{l}\text { Contraception prevalence } \\
\text { rate (CPR) }\end{array}$ & $\begin{array}{l}\text { Proportion of married or in-union } \\
\text { women using any modern method of } \\
\text { contraception, country specific data }\end{array}$ & $\begin{array}{l}\text { UN, Department of Economic and } \\
\text { Social Affairs, Population Division, } \\
2019 \text { [25] }\end{array}$ & $\begin{array}{l}\text { Most recent survey year data available } \\
\text { was used }\end{array}$ \\
\hline Annual pregnancy rate (PR) & $\begin{array}{l}\text { Pregnancy rate among women among } \\
\text { women aged } 15-44 \text {, sub-regional data }\end{array}$ & Sedgh et al., 2016 [26] & $\begin{array}{l}\text { Pregnancies include all live births, } \\
\text { abortions, and miscarriages }\end{array}$ \\
\hline $\begin{array}{l}\text { Contraceptive method } \\
\text { mix (CMM) }\end{array}$ & $\begin{array}{l}\text { The proportion of total family planning } \\
\text { users using each modern method of } \\
\text { contraception, country specific data }\end{array}$ & $\begin{array}{l}\text { Family Planning } 2020 \text { (FP2020), } \\
2019 \text { [22] }\end{array}$ & $\begin{array}{l}\text { Modern methods include sterilization } \\
\text { (female), sterilization (male), IUD, } \\
\text { implant, injectable, pill, male condoms, } \\
\text { and Lactational Amenorrhea Method } \\
\text { (LAM) }\end{array}$ \\
\hline $\begin{array}{l}\text { Contraceptive method- } \\
\text { specific failure rates }\end{array}$ & $\begin{array}{l}\text { Median failure rate in first } 12 \text { months } \\
\text { of use by method }\end{array}$ & Guttmacher Institute, 2016 [23] & $\begin{array}{l}\text { Uses DHS survey data from } 43 \\
\text { countries, 1990-2013 }\end{array}$ \\
\hline ART coverage for PMTCT & $\begin{array}{l}\text { Proportion of pregnant WLHIV who } \\
\text { receive ART for PMTCT, country } \\
\text { specific data }\end{array}$ & UNAIDS, 2018 [1] & $\begin{array}{l}\text { Where } 2018 \text { UNAIDS data were not } \\
\text { available, UNAIDS reports using } 2017 \\
\text { and } 2016 \text { data were used [27-29]. } \\
\text { Other sources include: the Centers } \\
\text { for Disease Control and Prevention } \\
\text { (CDC), USA [30]; Public Health } \\
\text { England, United Kingdom [31]; Clark, } \\
\text { 2017, Russia [32]. Countries with data } \\
\text { still missing were set at the UNAIDS } \\
\text { global average (0.82) }\end{array}$ \\
\hline $\begin{array}{l}\text { Annual birth rate } \\
15-49\end{array}$ & $\begin{array}{l}\text { Annual rate of live births to women } \\
15-49 \text { by country \& sub-region }\end{array}$ & $\begin{array}{l}\text { United Nations Population } \\
\text { Division [20] }\end{array}$ & $\begin{array}{l}\text { Used age-specific fertility rates and } \\
\text { female population by age to create } \\
\text { weighted annual births among } \\
\text { women } 15-49\end{array}$ \\
\hline $\begin{array}{l}\text { Proportion of births } \\
\text { unintended }\end{array}$ & $\begin{array}{l}\text { Proportion of births that arise from } \\
\text { unintended pregnancies, country-level } \\
\text { data }\end{array}$ & DHS Stat Compiler [21] & $\begin{array}{l}\text { For countries where DHS data were } \\
\text { not available or where DHS data } \\
\text { pre-dated 2000, the corresponding } \\
\text { sub-regional estimate from Bearak } \\
\text { et al., } 2018 \text { [8] was used }\end{array}$ \\
\hline
\end{tabular}

number of WLHIV (15-49) was < 10,000, given their negligible contribution to the final outcome of interest.

\section{Data analysis objective 1: calculating total new infant infections currently averted by contraception}

First, births averted by current contraception use among WLHIV were calculated as follows; where WLHIV is the number of WLHIV of reproductive age (15-49) [1], CPR is the national contraception prevalence rate [25], CFR is the country-specific contraception failure rate, $\mathrm{PR}$ is the annual pregnancy rate [26], and BR is the estimated live birth rate [20]:

Births averted by contraception use among WLHIV $=(W L H I V * C P R * P R-(C F R * W L H I V * C P R)) *\left(\frac{B R}{P R}\right)$

In this calculation, estimated CPR is not specific to WLHIV, instead taking into account the use any modern contraception method among married or in-union women [25]. Country-specific contraceptive failure rates (CFR) were calculated using the proportion of women using each modern contraceptive method [22] and the contraceptive method-specific failure rates [23] to calculate the average CFR for each country based on method mix. Countries without data on the proportion of women using each contraceptive method were assigned a CFR of 0.031. The represents a simple average of country CFRs with available data. Overall, country CFR ranged from 0.015 to 0.052 . Countries assigned the global CFR average $(n=25)$ are Argentina, Botswana, Brazil, China, Columbia, Dominican Republic, Ecuador, Equatorial Guinea, Eswatini, France, Gabon, Guatemala, Iran, Italy, Malaysia, Mexico, Namibia, Peru, Russian Federation, Spain, Thailand, Ukraine, United Kingdom, United States, and Venezuela.

Pregnancy and birth rates were calculated at the subregional level - referring to the division of continents into smaller geographic country groupings (e.g., Asia is split into Eastern, South-central, Southeastern, and Central regions). Pregnancy and birth rates were not universially available at the country-level. To adjust for the proportion of pregnancies which would not 
ultimately result in a live birth (due to spontaneous or induced abortion), sub-regional birth rates are divided by sub-regional pregnancy rates.

Next, the calculated number of births averted by contraception use among WLHIV in each country was used to estimate the number of new infant HIV infections that are currently being prevented by contraception. These calculations were completed in two parts: 1 ) Among births to WLHIV who were on ART during pregnancy, assuming 4\% transmission and; 2) Among births to WLHIV who were not on ART during pregnancy, assuming 30\% transmission [4]. ART coverage during pregnancy, labor, and breastfeeding (PMTCT coverage) was recorded from UNAIDS 2018 estimates [33]. Countries without data on PMTCT coverage (France, Italy, and Spain) were assigned the global average of 0.82 , and countries with coverage of $>0.95$ were assigned a value of 0.95 . The number of new infant HIV cases averted from births to women on and not on ART was calculated as follows, where PMTCT is countrylevel PMTCT coverage and BA_contraception is the number of births averted by contraception to WLHIV:

$$
\begin{aligned}
& \text { Total infant HIV cases averted by contraception } \\
& =\left(P M T C T * B A_{\text {contraception }} * 0.04\right) \\
& \quad+\left((1-P M T C T) * B A_{\text {contraception }} * 0.30\right)
\end{aligned}
$$

\section{Data analysis objective 2: calculating additional infant infections averted by preventing unintended births to WLHIV}

First, unintended births to WLHIV by country were calculated as follows, where WLHIV is the number of WLHIV of reproductive age (15-49), BR is the countrylevel live birth rate [20] among women, and pBU is the proportion of births which are estimated to be unintended [21]:

\section{Unintended birth to WLHIV $=W L H I V * B R * p B U$}

Here, both the country-level birth rate and the proportions of births which are estimated to be unintended are calculated for women overall and not specifically for WLHIV. These data are unavailable for WLHIV. The estimated country-level birth rate was found by weighting age-specific fertility rates by age-distributed population estimates for women 15-49 in each country [20].

Next, the number of unintended births to WLHIV in each country were used to estimate the additional infant HIV infections averted if unintended births to WLHIV were prevented. This was calculated separately for WLHIV currently on ART during pregnancy and not on ART during pregnancy as described above. Calculations were completed as follows, where PMTCT is country- level PMTCT coverage, and UB_WLHIV is the number of unintended births to WLHIV by country.

$$
\begin{aligned}
& \text { Total additional infant HIV infections averted } \\
& =\left(P M T C T * U B_{-} W L H I V * 0.04\right) \\
& \quad+\left((1-P M T C T) * U B_{-} W L H I V * 0.30\right)
\end{aligned}
$$

\section{Results}

\section{Contraceptive failure rates}

Among the 70 countries in this analysis, the estimated country-level contraception failure rate (CFR) was highest in the Central African Republic (52 per 1000 women using contraception), where the primary modern method used is the pill. This was closely followed by the Democratic Republic of the Congo (49 per 1000), where the primary modern method used is male condoms. CFRs were lowest in Uzbekistan (17 per 1000), where the primary modern method used is the IUD, followed by Ethiopia (18 per 1000), where higher proportions of women are using the implant compared toother African settings. In South Africa (CFR 30 per 1000), 47\% of modern contraception users are using an injectable birth control (data not shown see Additional file 1).

\section{New infant HIV infections currently averted by contraception}

Across the 70 included countries, current contraceptive use by WLHIV was estimated to be averting 43,559 new HIV infant infections annually (Fig. 1). Full results available in Additional file 2. Countries with the largest number of infant infections averted by contraception included South Africa (9441), Nigeria (4195), Kenya (3508), Zimbabwe (2586), and India (2145) (Table 2).

The majority of new infant cases $(24,440 / 43,559,56 \%)$ currently being averted by contraception were among women not receiving ART during pregnancy (untreated). However, contraception is still preventing a significant number of total new infant HIV cases $(19,119$ or $44 \%)$ among women who were on ART during pregnancy (treated). While the overall ratio of infant HIV cases averted among untreated vs. treated women was about $60: 40$, there was wide country variability. In some countries, such as Malawi, Zambia, and Mozambique, contraception is preventing over twice as many new infant infections among women on ART than women not on ART (1380 vs. $545 ; 1253$ vs. 494; and 1249 vs. 493 respectively).

\section{Potential infant HIV infections averted if unintended births among WLHIV were prevented}

Our model estimates an additional 43,768 new HIV cases could be averted annually if unintended births among WLHIV were prevented (Fig. 1). Countries with 


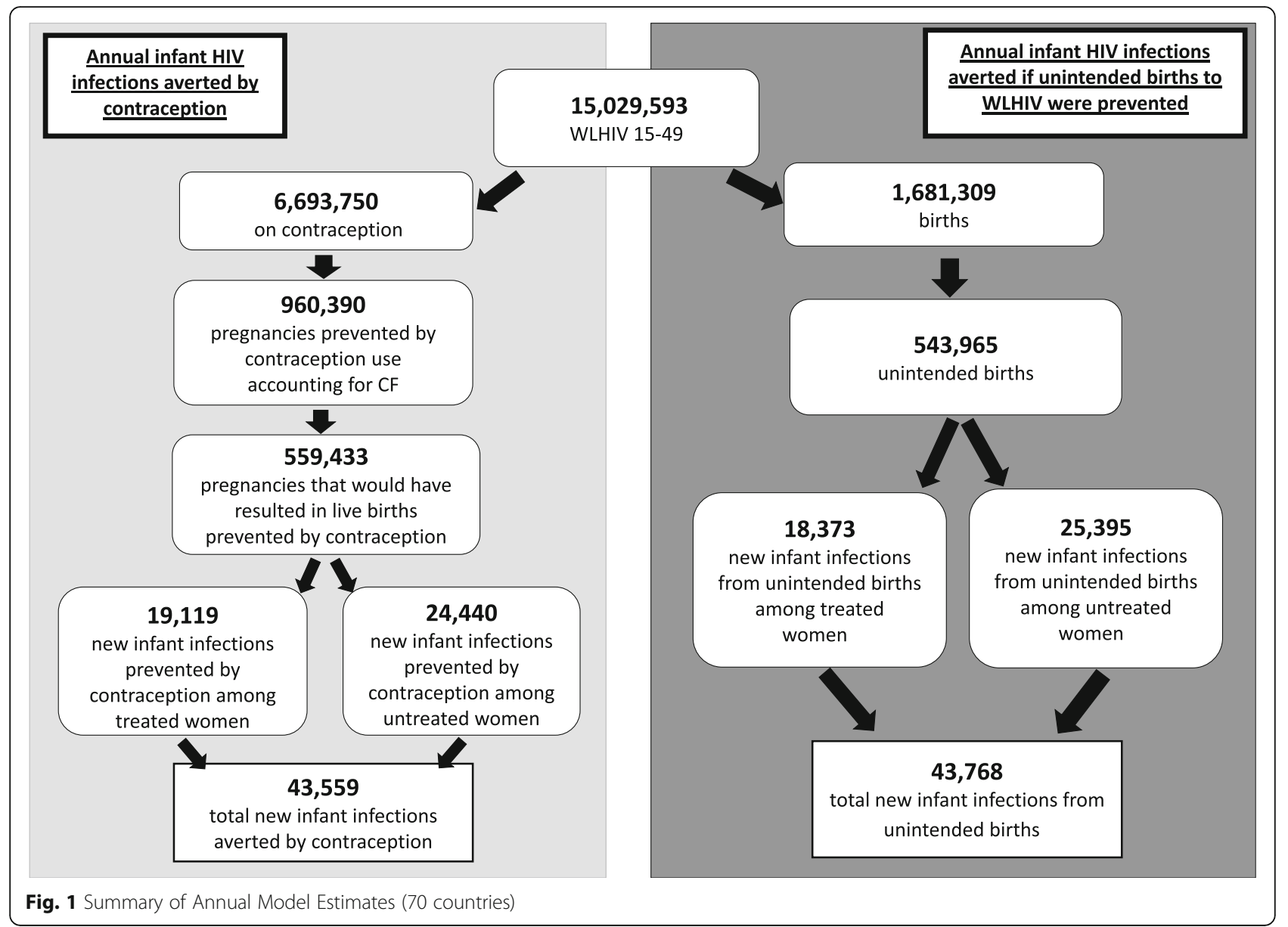

the largest number of potential gains to be made in preventing infant HIV cases are in sub-Saharan Africa including South Africa (12,036), Nigeria (2770), Uganda (2552), the Democratic Republic of the Congo (2324), and Angola (2147) (Table 3). Full results are available in Additional file 3.

If all unintended births to WLHIV were prevented, the largest number of new infant HIV infections averted would be to women not on ART $(25,395$ / 43,768, or $58 \%)$. However, gains would also be made among women on ART, with an additional 18,373 (42\%) new infant HIV infections averted among women on ART. Again, there was significant country variability with many countries $(25 / 70,36 \%)$ projected to prevent more infant HIV infections among women on ART than women not on ART if all unintended births were prevented. Of note, countries that have greater than or equal to $95 \%$ coverage of ART for pregnant women in our analysis $(n=17 / 70)$ account for $14 \%(6098 / 43,768)$ of the additional infant infections that could be averted if unintended births to WLHIV were prevented.

\section{Discussion}

The results of this analysis show the central role contraception continues to play in preventing new infant HIV infections in the era of increased ART coverage - estimating that contraception is preventing 43,559 infant infections per year in 70 countries. In comparison to previous estimates from 2005 to 2009 [18, 34-36], the current model finds a smaller overall number of infant infections averted by contraception (43,000 vs. 200,000 in PEPFAR countries). This is an unsurprising result given the increase in ART coverage in the past decade. Indeed, since 2010, global ART coverage during pregnancy has increased from 44 to $82 \%$ with the largest gains made in Southern and Eastern Africa [1]. However, our results do show similar geographical rankings as previous models, with Southern and Eastern Africa remaining the regions with the greatest potential to prevent infant HIV infections by preventing unintended births.

ART coverage is fundamental for protecting women's own health and remains a top priority in fighting the 
Table 2 Number of HIV positive births averted by contraception annually, top 30 countries

\begin{tabular}{|c|c|c|c|c|c|c|c|}
\hline \multirow[t]{2}{*}{ Country } & \multirow[t]{2}{*}{ WLHIV aged $15-49^{a}(A)$} & \multirow[t]{2}{*}{$\begin{array}{l}\text { WLHIV (15-49) on modern } \\
\text { contraception }^{\text {b }} \text { (B) }\end{array}$} & \multirow{2}{*}{$\begin{array}{l}\text { Pregnancies to } \\
\text { WLHIV averted by } \\
\text { contraception }^{c} \text { (C) }\end{array}$} & \multirow[t]{2}{*}{$\begin{array}{l}\text { Births to WLHIV averted } \\
\text { by contraception }{ }^{d} \text { (D) }\end{array}$} & \multicolumn{3}{|c|}{$\begin{array}{l}\text { HIV- positive births } \\
\text { averted by contraception }\end{array}$} \\
\hline & & & & & Treated & Untreated & Total \\
\hline South Africa & $4,050,000$ & $2,187,000$ & 204,530 & 127,930 & 4452 & 4989 & 9441 \\
\hline Nigeria & 860,000 & 161,680 & 36,138 & 22,604 & 398 & 3798 & 4195 \\
\hline Kenya & 740,000 & 434,380 & 96,648 & 55,337 & 2014 & 1494 & 3508 \\
\hline Zimbabwe & 600,000 & 394,800 & 81,224 & 46,506 & 1749 & 837 & 2586 \\
\hline India & 655,544 & 313,350 & 26,808 & 14,898 & 358 & 1788 & 2145 \\
\hline Malawi & 480,000 & 278,880 & 63,411 & 36,307 & 1380 & 545 & 1924 \\
\hline Uganda & 650,000 & 235,950 & 52,899 & 30,288 & 1127 & 636 & 1763 \\
\hline Indonesia & 217,800 & 128,066 & 12,919 & 6709 & 40 & 1711 & 1751 \\
\hline Zambia & 580,000 & 259,260 & 57,572 & 32,963 & 1253 & 494 & 1747 \\
\hline Mozambique & $1,060,000$ & 268,180 & 57,384 & 32,856 & 1249 & 493 & 1741 \\
\hline Tanzania & 720,000 & 230,400 & 50,511 & 28,921 & 1076 & 607 & 1683 \\
\hline Ethiopia & 324,000 & 122,472 & 27,981 & 16,021 & 590 & 384 & 974 \\
\hline Cameroon & 277,000 & 58,170 & 13,972 & 8748 & 280 & 525 & 805 \\
\hline Angola & 179,000 & 22,375 & 5549 & 3474 & 53 & 646 & 699 \\
\hline Brazil & 244,313 & 189,831 & 16,895 & 8172 & 278 & 368 & 646 \\
\hline Ghana & 170,000 & 42,500 & 9822 & 6144 & 194 & 387 & 581 \\
\hline Lesotho & 152,000 & 90,896 & 7737 & 4840 & 149 & 334 & 483 \\
\hline DRC & 234,000 & 17,550 & 4105 & 2570 & 45 & 432 & 477 \\
\hline Mali & 74,000 & 11,174 & 2607 & 1631 & 16 & 372 & 387 \\
\hline Eswatini & 103,000 & 67,465 & 6274 & 3924 & 124 & 247 & 371 \\
\hline Côte d'Ivoire & 205,000 & 40,180 & 8682 & 5431 & 195 & 163 & 358 \\
\hline Thailand & 170,000 & 128,350 & 12,322 & 6399 & 243 & 96 & 339 \\
\hline Rwanda & 103,000 & 48,925 & 10,823 & 6197 & 235 & 93 & 328 \\
\hline Congo & 46,900 & 8677 & 1999 & 1252 & 13 & 282 & 294 \\
\hline U.S. & 226,698 & 153,475 & 10,590 & 5509 & 209 & 83 & 292 \\
\hline Russia & 278,415 & 153,128 & 12,097 & 5068 & 193 & 76 & 269 \\
\hline Botswana & 159,000 & 81,408 & 7571 & 4736 & 180 & 71 & 251 \\
\hline Madagascar & 18,578 & 7171 & 1613 & 924 & 4 & 247 & 251 \\
\hline Myanmar & 85,000 & 43,605 & 4287 & 2226 & 71 & 134 & 205 \\
\hline Viet Nam & 60,000 & 39,000 & 3706 & 1925 & 62 & 110 & 172 \\
\hline
\end{tabular}

a Calculated as women living with HIV aged 15+- WLHIV aged 50+

${ }^{b}$ Calculated as $A *$ Contraceptive prevalence rate

C Calculated as ( $B$ * pregnancy rate) - (B* contraception failure rate)

${ }^{d}$ Calculated as $C *$ proportion of pregnancies resulting in live birth (birth rate/pregnancy rate)

${ }^{f}$ Calculated as ( $D *$ Coverage of pregnant women for preventing mother-to-child transmission [PMTCT])* 0.04 estimated transmission among those on treatment $)+\left(D^{*}(1\right.$ - coverage of pregnant women for PMTCT $) * 0.30$ estimated transmission among those not on treatment)

HIV pandemic. However, current results show that even in the context of continued scale-up of ART, contraception plays a significant role in the prevention of new infant HIV infections. For example, South Africa has relatively high ART coverage of women during pregnancy $(>87 \%)$, which prevents the majority of new infant infections. However, over 12,000 additional infant HIV cases could be averted annually in South Africa if unintended births to WLHIV were prevented with voluntary contraceptive access. Even in countries where ART coverage for PMTCT is excellent $(\geq 95 \%)$, unintended births still contribute around $14 \%$ of new infant infections. Results demonstrate that improving contraceptive access remains critical to prevent HIV even in these settings with high ART coverage. To meet the health needs of WLHIV and end MTCT, it is critical 
Table 3 Number of additional infant HIV infections averted if unintended births to WLHIV were prevented, top 30 countries

\begin{tabular}{|c|c|c|c|c|c|c|}
\hline \multirow[t]{2}{*}{ Country } & \multirow[t]{2}{*}{$\begin{array}{l}\text { No of WLHIV } \\
\text { aged } 15-49^{\mathrm{a}}(\mathrm{A})\end{array}$} & \multirow[t]{2}{*}{$\begin{array}{l}\text { No of births to } \\
\text { WLHIV annually }{ }^{b} \text { (B) }\end{array}$} & \multirow[t]{2}{*}{$\begin{array}{l}\text { No of unintended births } \\
\text { to WLHIV annuallyc }\end{array}$} & \multicolumn{3}{|c|}{$\begin{array}{l}\text { Total new infant infections from } \\
\text { unintended births to WLHIV }\end{array}$} \\
\hline & & & & Treated & Untreated & Total \\
\hline South Africa & $4,050,000$ & 302,024 & 163,093 & 5676 & 6361 & 12,036 \\
\hline Nigeria & 860,000 & 142,123 & 14,923 & 263 & 2507 & 2770 \\
\hline Uganda & 650,000 & 105,659 & 43,848 & 1631 & 921 & 2552 \\
\hline DRC & 234,000 & 43,479 & 12,522 & 220 & 2104 & 2324 \\
\hline Angola & 179,000 & 31,753 & 10,669 & 162 & 1984 & 2147 \\
\hline Tanzania & 720,000 & 112,564 & 34,895 & 1298 & 733 & 2031 \\
\hline Kenya & 740,000 & 82,445 & 29,433 & 1071 & 795 & 1866 \\
\hline Zambia & 580,000 & 86,809 & 33,335 & 1267 & 500 & 1767 \\
\hline Malawi & 480,000 & 67,712 & 27,694 & 1052 & 415 & 1468 \\
\hline Mozambique & $1,060,000$ & 167,026 & 24,720 & 939 & 371 & 1310 \\
\hline Zimbabwe & 600,000 & 69,895 & 22,716 & 854 & 409 & 1263 \\
\hline Cameroon & 277,000 & 40,647 & 9633 & 308 & 578 & 886 \\
\hline Lesotho & 152,000 & 15,567 & 8017 & 247 & 553 & 800 \\
\hline South Sudan & 87,000 & 12,901 & 4773 & 107 & 630 & 737 \\
\hline Ethiopia & 324,000 & 43,585 & 11,071 & 407 & 266 & 673 \\
\hline Eswatini & 103,000 & 9982 & 6359 & 201 & 401 & 602 \\
\hline Ghana & 170,000 & 20,201 & 6242 & 197 & 393 & 590 \\
\hline Indonesia & 217,800 & 14,774 & 2246 & 13 & 573 & 586 \\
\hline India & 655,544 & 45,359 & 3946 & 95 & 474 & 568 \\
\hline Brazil & 244,313 & 12,491 & 6870 & 234 & 309 & 543 \\
\hline Côte d'Ivoire & 205,000 & 30,598 & 7405 & 267 & 222 & 489 \\
\hline Mali & 74,000 & 13,867 & 1941 & 19 & 443 & 461 \\
\hline Congo & 46,900 & 6392 & 1796 & 18 & 404 & 422 \\
\hline Botswana & 159,000 & 14,168 & 7651 & 291 & 115 & 406 \\
\hline Haiti & 73,000 & 6685 & 3790 & 126 & 193 & 319 \\
\hline Namibia & 87,000 & 9485 & 4847 & 184 & 73 & 257 \\
\hline Rwanda & 103,000 & 12,931 & 4629 & 176 & 69 & 245 \\
\hline U.S & 226,698 & 13,041 & 4564 & 173 & 68 & 242 \\
\hline CAR & 48,000 & 7353 & 2059 & 58 & 179 & 238 \\
\hline Equatorial Guinea & 26,300 & 3984 & 1116 & 22 & 167 & 190 \\
\hline
\end{tabular}

${ }^{a}$ Calculated as women living with HIV (WLHIV) aged 15+- WLHIV aged 50+

${ }^{b}$ Calculated as $A^{*}$ annual birth rate

c Calculated as B* proportion of births that are unintended

${ }^{d}$ Calculated as $(C *$ coverage of pregnant women for PMTCT * 0.04 estimated transmission among those on treatment $)+(C *(1-$ coverage of pregnant women for PMTCT $)^{*} 0.3$ estimated transmission among those on treatment)

that both voluntary efforts to expand ART coverage for WLHIV and prevent unintended pregnancies are aggressively implemented.

UNAIDS and PEPFAR established the goal of reducing the annual number of children newly infected with HIV to fewer than 20,000 by 2020 in their "Start Free, Stay Free, AIDS Free" framework [33]. While progress has been made, the world has not yet met this goal. In 2018, 160,000 children were newly diagnosed with HIV and global ART coverage for PMTCT remained at 82\% [33].
As work to close this gap intensifies, meeting the voluntary contraceptive needs of WLHIV must remain a central pillar of this effort. One avenue to help meet this goal is to increase integration of ART for PMTCT and family planning programming. Strategies for integration include providing both services in the same location or through active coordinated care referral systems [37]. A number of studies have demonstrated integration of these services resulted in increased contraception uptake, increased use of more effective methods, and 
reduced pregnancy rates among those at risk for or living with HIV [38-41]. Strong international and national funding for family planning services is also critical. Contraceptive stock outs and shortages are common globally and unmet need for contraception continues to outpace global funding for contraceptive commodities [42]. National governments and donors who are serious about goals to end MTCT will also prioritize meeting women's contraceptive needs as a key strategy post-2020.

In addition to increasing access to any modern method of contraception, expanding the variety of contraceptive methods available may also play a role in increasing overall contraceptive prevalence [7]. Many countries included in this analysis have a skewed contraceptive method mix, where $50 \%$ or more of modern contraception users rely on a single method. Ensuring women have a variety of options to meet reproductive needs and preferences may encourage overall contraception use. Many donors, particularly those with country focuses, have invested in the scale-up of a single contraceptive method, an investment that can inadvertently skew method mix [43]. While commitment to novel and underused methods is commendable, donors and national governments must coordinate to provide method mix of desired contraceptives not at a national, but at a clinical and site level [14]. The thoughtful global consensus language found in FP 2020 commitments [44] still requires more actualizing to make sure that the informed choice of individuals is supported by actual commodity choice at the clinic.

The value of increased CMM is in providing greater choice to users and extends beyond HIV prevention, but could also lower CFR. The modern methods included in the analysis had an estimated range of CFR from 0.06 for the pill to 0.01 for both IUDs and implants [23]. While the more effective contraception methods with lower CFR may not be preferable or appropriate for all women, ensuring access should they want them is a valuable strategy to lower CFR and decrease unwanted births to WLHIV and others. Long-acting reversible contraception (LARC) uptake is on the rise in SubSaharan Africa, yet gains have been more significant among wealthier, higher educated, and urban women [45], leaving gaps in availability and accessibility for many groups of women that may also be less likely to have access to effective ART during pregnancy. Addressing barriers related to awareness, supply, and provider training are all of importance in ensuring access to women's desired form of contraception.

There are several limitations to this analysis. While every effort was made to use consistent and quality data sources across countries, data gaps prompted some differential use of data by country, survey type, or year of data collection. Firstly, country-level data was not available for all indicators. In these cases, sub-regional data were used, which may have masked country-level disparities. Secondly, data on CFR and PMTCT coverage were missing for 25 and 3 countries respectively. In these cases, missing data was imputed with global averages. Mean imputation of these values may have again reduced differences between countries. However, countries with imputed data $(n=28)$ only contribute approximately 2600 events (6\%) to the estimated 43,559 new HIV infant infections averted annually by contraceptive use. Relatively minor adjustments to imputed data for these countries would not greatly alter the overall estimation of infant infections adverted. Thirdly, many of the secondary datasets used in this analysis are themselves modelled and include uncertainty bounds. For example, UNAIDS HIV prevalence estimates for women are reported as a range. In these cases, our models used the median point estimates, which may have resulted in over or under estimations of the final outcome of interest.

For some indicators, including annual birth rate, annual pregnancy rate, proportion of births unintended, contraceptive prevalence rate, and CMM, country-level data specific to WLHIV are unavailable. In these cases, data from the overall population of women were substituted. Existing literature suggests there may be differences for these indicators between WLHIV and the general population of women which may affect model estimates. For example, WLHIV may have a higher [46, 47] or lower [48] overall contraceptive prevalence rate compared to the general population. These size of these differences vary by country. For example, in Tanzania, WLHIV were found to have a contraception prevalence of $54 \%$ compared to $32 \%$ in the general population [46] while among WLHIV in Togo, contraception prevalence was $74.7 \%$ compared to $19.9 \%$ in the general population [47]. WLHIV may also have more difficulty accessing diverse contraception methods [49], resulting in a different CCM and CFR as compared to a country's general population. WLHIV also may have a different rate of unintended births [50]. It is difficult to confirm if these differences contributed to an under or overestimation of the outcomes. Finally, this model only includes births to women aged 15-49, however births can occur to women over 50 and under 15 [51], which are not included, but likely contributed to an underestimation of total infant HIV infections averted.

\section{Conclusion}

The analysis shows that contraception continues to play a significant role in the prevention of new infant HIV infections even in the era of increasing global ART 
coverage. Continued progress towards global goals to end MTCT will rely on the continued scale-up of ART coverage for women as well as ensuring the availability of contraception for women wishing to prevent pregnancy. Increasing CMM to meet the diverse needs of women is a necessity and should be seen as integral to both the effort to end HIV in children and the women's health movement.

\section{Abbreviations}

ART: Antiretroviral therapy; BR: Birth rate; CMM: Contraceptive method mix; CPR: Contraceptive prevalence rate; DHS: Demographic Health Survey; HIV: Human Immunodeficiency Virus; IUD: Intrauterine Device; LARC: Longacting reversible contraception; MTCT: Mother to child transmission; PEPF AR: President's Emergency Plan for AIDS Relief; PMTCT: Prevention of mother to child transmission; PR: Pregnancy rate; UNAIDS: United Nations Programme on HIV/AIDS; WLHIV: Women living with HIV

\section{Supplementary Information}

The online version contains supplementary material available at https://doi. org/10.1186/s12889-021-10570-w.

Additional file 1.

Additional file 2.

Additional file 3.

\section{Acknowledgements}

Thank you to amfAR, the Foundation for AIDS Research and CHANGE for supporting this work.

\section{Authors' contributions}

JS, BR and BH conceptualized and designed the analysis. JS and EL led data collection and data analysis. JS led and assembled the manuscript, with critical sections written by EL, BR, BC, and AJ. All authors contributed to editing the manuscript. The author(s) read and approved the final manuscript

\section{Funding}

amfAR and CHANGE supported staff time to conduct this analysis and develop the manuscript. There was no external funding source for this work.

\section{Availability of data and materials}

Pre-downloaded data sets are available from the corresponding author on reasonable request. Datasets used for the estimates of women living with HIV are available from UNAIDS [https://aidsinfo.unaids.org/] [1] and the Global Health Data Exchange [http://ghdx.healthdata.org/gbd-results-tool201 7] [24]. The dataset used for contraception prevalence is available from the UNDP [https:/www.un.org/en/development/desa/population/publications/ dataset/contraception/wcu2019/UNPD_WCU2019_Country_Data_SurveyBased.xlsx] [25]. The dataset for pregnancy rate is available from Sedgh et al. [https://doi.org/10.1111/j.1728-4465.2014.00393.x] [26]. The dataset used for contraception method mix is available from Family Planning 2020 [http:// progress.familyplanning2020.org/resources2019] [22]. The dataset used for contraception failure rates is available from the Guttmacher Institute [https:// www.guttmacher.org/report/contraceptive-failure-rates-in-developing-world] [23]. The dataset used for PMCTCT Coverage is available from UNAIDS [https://aidsinfo.unaids.org/] [1]. Additional PMTCT data were from the CDC [https://www.cdc.gov/hiv/group/gender/pregnantwomen/index.html] [30], Public Health England [https://assets.publishing.service.gov.uk/government/ uploads/system/uploads/attachment_data/file/602942/HIV_in_the_UK_report pdf] [31], and Clark [https://doi.org/10.1016/S0140-6736(16)31480-5] [32]. The dataset used for birth rates is available from the UNDP [https://population. un.org/wpp/Download/Standard/Population/] [20]. The dataset used for unintended births is available from the DHS Stat Compiler [http://www. statcompiler.com] [21]. Additional unintended births data is from Bearak et al. [https://doi.org/10.1016/S2214-109X(18)30029-9] [8].

\section{Declarations}

\section{Ethics approval and consent to participate}

Ethical approval for human subject's research was not required for this secondary analysis of publicly available data sets with no identifiable information.

\section{Consent for publication}

Not applicable.

\section{Competing interests}

The authors declare that they have no competing interests.

\section{Author details}

'Public Policy Office, amfAR, Foundation for AIDS Research, 1100 Vermont Avenue NW, Suite 600, District of Columbia, Washington, DC 20005, USA. ${ }^{2}$ Department of Population, Family, and Reproductive Health, Johns Hopkins Bloomberg School of Public Health, Baltimore, MD, USA. ${ }^{3}$ Center for Health and Gender Equity (CHANGE), Washington DC, USA.

Received: 9 September 2020 Accepted: 7 March 2021

Published online: 19 March 2021

\section{References}

1. AIDSinfo. Joint United Nations Programme on HIV and AIDS. 2018. https://a idsinfo.unaids.org/. Accessed 15 July 2020.

2. Children, HIV and AIDS: Global snapshot. United Nations Children's Fund (UNICEF). 2019. https://data.unicef.org/resources/children-hiv-aids-global-sna pshot/. Accessed 15 July 2020.

3. World Health Organization (WHO). PMTCT Strategic Vision 2010-2015: preventing mother-to-child transmission of HIV to reach the UNGASS and Millennium Development Goals. Geneva: WHO Press; 2010.

4. Flynn PM, Abrams EJ, Fowler, MG. Prevention of mother-to-child transmission in resource-limited settings. UpToDate. 2020. https://www. uptodate.com/contents/prevention-of-mother-to-child-hiv-transmission-inresource-limited-settings. Accessed 15 July 2020.

5. Rana MJ, Goli S. Tracing long-term trajectories of contraceptive practice across 185 countries. PLoS One. 2018;13:10.

6. Darrock J. Adding it up: investing in contraception and maternal and newborn health. Guttmacher Institute; 2018.

7. Ross J, Stover J. Use of modern contraception increases when more methods become available: analysis of evidence from 1982-2009. Glob Health Sci Pract. 2013;1:2.

8. Bearak J, Popinchalk A, Alkema L, Sedgh G. Global, regional, and subregional trends in unintended pregnancy and its outcomes from 1990 to 2014: estimates from a Bayesian hierarchical model. Lancet Glob Health. 2018;6:4.

9. Campbell AA, Mosher WD. A history of the measurement of unintended pregnancies and births. Matern Child Health J. 2000;4:3.

10. Tsui AO, McDonald-Mosley R, Burke AE. Family planning and the burden of unintended pregnancies. Epidemiol Rev. 2010;32:1.

11. Hardee K, Kumar J, Newman K, Bakamjian L, Harris S, Rodríguez M, Brown W. Voluntary, human rights-based family planning: a conceptual framework. Stud Fam Plan. 2014;45(1):1-18. https://doi.org/10.1111/j.172 8-4465.2014.00373.x.

12. Bi S, Klusty T. Forced sterilizations of HIV-positive women: a global ethics and policy failure. AMA J Ethics. 2015;17:10.

13. Rowlands S, Amy J-J. Non-consensual sterilization of women living with HIV. Int J STD AIDS. 2018;29:9.

14. World Health Organization (WHO). Ensuring human rights in the provision of contraceptive information and services: guidance and recommendations. Geneva: WHO Press; 2014.

15. Ahmed S, Li Q, Liu L, Tsui AO. Maternal deaths averted by contraceptive use: an analysis of 172 countries. Lancet. 2012;380:9837.

16. Cleland J, Conde-Agudelo A, Peterson H, Ross J, Tsui A. Contraception and health. Lancet. 2012;380:9837.

17. Petruney T, Robinson E, Reynolds H, Wilcher R, Cates W. Contraception is the best kept secret for prevention of mother-to-child HIV transmission. Bull World Health Organ. 2008;86:6.

18. Reynolds HW, Janowitz B, Wilcher R, Cates W. Contraception to prevent HIVpositive births: current contribution and potential cost savings in PEPFAR countries. Sex Transm Infect. 2008;84(Suppl 2):ii49-53. 
19. Stover J, Glaubius R, Mofenson L, Dugdale CM, Davies M-A, Patten G, Yiannoutsos C. Updates to the Spectrum/AIM model for estimating key HIV indicators at national and subnational levels. AIDS. 2019;33(Supplement 3): S227-34. https://doi.org/10.1097/QAD.0000000000002357.

20. World Population Prospects. United Nations Population Division. 2019. https://population.un.org/wpp/Download/Standard/Population/. Accessed 15 July 2020.

21. The DHS Program STATcompiler. The Demographic and Health Surveys Program http://www.statcompiler.com. Accessed 15 July 2020.

22. 2018-2019 Progress Report Estimate Tables. Family Planning 2020. 2019. http://progress.familyplanning2020.org/resources2019. Accessed 15 July 2020

23. Polis C, Bradley S, Bankole A, Onda T, Croft TN, Singh S. Contraceptive failure rates in the developing world: an analysis of demographic and health survey data in 43 countries. Guttmacher Institute; 2016.

24. Global Burden of Disease Results Tool. Global Health Data Exchange. http:// ghdx.healthdata.org/gbd-results-tool2017. Accessed 15 July 2020.

25. World Contraception Use 2019. United Nationas Population Division 2019. https://www.un.org/en/development/desa/population/publications/dataset/ contraception/wCU2019/UNPD_WCU2019_Country_Data_Survey-Based.xlsx. Accessed 15 July 2020.

26. Sedgh G, Singh S, Hussain R. Intended and unintended pregnancies worldwide in 2012 and recent trends. Stud Fam Plan. 2014:45:3.

27. Joint United Nations Programme on HIV and AIDS (UNAIDS). UNAIDS data 2018. UNAIDS: 2018

28. Joint United Nations Programme on HIV/AIDS (UNAIDS). UNAIDS Data 2017 UNAIDS: 2017

29. Joint United Nations Programme on HIV/AIDS (UNAIDS). Country progress report - China. UNAIDS: 2018.

30. HIV and Pregnant Women, Infants, and Children 2019. Centers for Disease Control and Prevention (CDC) 2019. https://www.cdc.gov/hiv/group/ gender/pregnantwomen/index.html. Accessed 15 July 2020.

31. Public Health England. HIV in the UK 2016 report. London: Public Health England; 2016.

32. Clark F. Gaps remain in Russia's response to HIV/AIDS. Lancet. 2016; 388(10047):857-8. https://doi.org/10.1016/S0140-6736(16)31480-5.

33. Joint United Nations Programme on HIV/AIDS (UNAIDS). Start Free Stay Free AIDS Free 2019. UNAIDS: 2019.

34. Reynolds HW, Steiner MJ, Cates W Jr. Contraception's proved potential to fight HIV. Sex Transm Infect. 2005;81(2):184-5. https://doi.org/10.1136/sti.2 004.012013 .

35. Halperin DT, Stover J, Reynolds HW. Benefits and costs of expanding access to family planning programs to women living with HIV. AIDS. 2009;23(Suppl 1):S123-S30. https://doi.org/10.1097/01.aids.0000363785.73450.5a.

36. Hladik W, Stover J, Esiru G, Harper M, Tappero J. The contribution of family planning towards the prevention of vertical HIV transmission in Uganda. PLoS One. 2009;4:11.

37. Haberlen SA, Narasimhan M, Beres LK, Kennedy CE. Integration of family Planning services into HIV care and treatment services: a systematic review. Stud Fam Plan. 2017:48:2.

38. Peck R, Fitzgerald DW, Liautaud B, Deschamps MM, Verdier RI, Beaulieu ME, et al. The feasibility, demand, and effect of integrating primary care services with HIV voluntary counseling and testing: evaluation of a 15-year experience in Haiti, 1985-2000. J Acquir Immune Defic Syndr. 2003;33:4.

39. Grossman D, Onono M, Newmann SJ, Blat C, Bukusi EA, Shade SB, Steinfeld $R L$, Cohen CR. Integration of family planning services into HIV care and treatment in Kenya: a cluster-randomized trial. AIDS. 2013;27(Suppl 1):S7785. https://doi.org/10.1097/QAD.0000000000000035.

40. Baumgartner JN, Green M, Weaver MA, Mpangile G, Kohi TW, Mujaya SN, et al. Integrating family planning services into HIV care and treatment clinics in Tanzania: evaluation of a facilitated referral model. Health Policy Plann. 2014;29:5.

41. Cohen CR, Grossman D, Onono M, Blat C, Newmann SJ, Burger RL, et al. Integration of family planning services into HIV care clinics: Results one year after a cluster randomized controlled trial in Kenya. PLoS One. 2017;12(3): e0172992.

42. United States Agency for International Development (USAID). USAID Global Health Supply Chain Program: 2017 Contraceptive security indicators report. USAID: 2018

43. Collaboration helps broaden access to Pfiezer's contrsceptive, Sayana ${ }^{\circledR}$ Press (Medroxylprogesterone acetate), for women in some of the world's poorest countries [press release]. Pfizer, Inc. 2017. https://www.pfizer.com/news/pressrelease/press-release-detail/collaboration_helps_broaden_access_to_pfizer_s_ contraceptive_sayana_press_medroxyprogesterone_acetate_for_women_in_ some_of_the_world_s_poorest_countries. Accessed 15 July 2020.

44. Family Planning 2020. Global consensus statement for expanding contraceptive choice for adolescents and youth to include long-acting reversible contraception. Family Planning 2020: 2015.

45. Adedini SA, Omisakin OA, Somefun OD. Trends, patterns and determinants of long-acting reversible methods of contraception among women in subSaharan Africa. PLoS One. 2019;14:6;e0217574.

46. Damian DJ, George JM, Martin E, Temba B, Msuya SE. Prevalence and factors influencing modern contraceptive use among HIV-positive women in Kilimanjaro region, northern Tanzania. Contracept Reprod Med. 2018;3(1): 7. https://doi.org/10.1186/s40834-018-0060-2.

47. Yaya I, Patassi AA, Landoh DE, Bignandi EM, Kolani K, Namoro A-DD, et al. Modern contraceptive use among HIV-infected women attending HIV care centres in Togo: a cross-sectional study. BMJ Open. 2018;8:4.

48. Wekesa E, Coast E. Contraceptive need and use among individuals with HIV/AIDS living in the slums of Nairobi, Kenya. Int J Gynecol Obstet. 2015; 130(Suppl 3):e31-6.

49. Church K, Wringe A, Fakudze P, Kikuvi J, Nhlabatsi Z, Masuku R, et al. Reliance on condoms for contraceptive protection among HIV care and treatment clients: a mixed methods study on contraceptive choice and motivation within a generalised epidemic. Sex Transm Infect. 2014;90:5.

50. McCoy SI, Buzdugan R, Ralph L, Mushavi A, Mahomva A, Hakobyan A, et al. Unmet need for family planning, contraceptive failure, and unintended pregnancy among HIV-infected and HIV-uninfected women in Zimbabwe. PLoS One. 2014;9:8.

51. Neal S, Matthews Z, Frost M, Fogstad H, Camacho AV, Laski L. Childbearing in adolescents aged 12-15 years in low resource countries: a neglected issue. New estimates from demographic and household surveys in 42 countries. Acta Obstet Gynecol Scand. 2012;91:9.

\section{Publisher's Note}

Springer Nature remains neutral with regard to jurisdictional claims in published maps and institutional affiliations.

Ready to submit your research? Choose BMC and benefit from

- fast, convenient online submission

- thorough peer review by experienced researchers in your field

- rapid publication on acceptance

- support for research data, including large and complex data types

- gold Open Access which fosters wider collaboration and increased citations

- maximum visibility for your research: over $100 \mathrm{M}$ website views per year

At $\mathrm{BMC}$, research is always in progress.

Learn more biomedcentral.com/submissions 